\title{
Effect of five dental pulp capping agents on cell proliferation, viability, apoptosis and mineralization of human dental pulp cells
}

\author{
LEI DOU $^{1-3 *}$, QIFANG YAN ${ }^{4 *}$ and DEQIN YANG ${ }^{1-3}$ \\ ${ }^{1}$ Department of Conservative Dentistry and Endodontics, Stomatological Hospital of Chongqing Medical University; \\ ${ }^{2}$ Chongqing Key Laboratory of Oral Diseases and Biomedical Sciences; ${ }^{3}$ Chongqing Municipal Key Laboratory of Oral \\ Biomedical Engineering of Higher Education, Chongqing 401147; ${ }^{4}$ Department of Endodontics, The Affiliated \\ Stomatology Hospital of Southwest Medical University, Luzhou, Sichuan 646000, P.R. China
}

Received March 7, 2019; Accepted September 19, 2019

DOI: $10.3892 /$ etm.2020.8444

\begin{abstract}
The aim of the present study was to investigate the effect of calcium hydroxide $\left[\mathrm{Ca}(\mathrm{OH})_{2}\right]$, mineral trioxide aggregate (MTA), iRoot BP, platelet-rich fibrin (PRF) and concentrated growth factors (CGF) on the proliferation, viability, apoptosis and mineralization of human dental pulp cells (HDPCs). HDPCs were treated with $\mathrm{Ca}(\mathrm{OH})_{2}$, MTA, iRoot BP, PRF and CGF exudates. Cell viability, apoptosis, proliferation, cell cycle and alkaline phosphatase (ALP) activity were evaluated in vitro. PRF significantly increased the cell proliferation as compared with that in the MTA and iRoot BP groups on day 3. The CGF group displayed higher proliferation rates as compared with that in the MTA group on days 3 and 7. The MTA group displayed the highest ALP activity on days 1 and 3 , and the CGF group on day 7. $\mathrm{Ca}(\mathrm{OH})_{2}$ inhibited cell proliferation and the percentages of dead and apoptotic cells were relatively higher in the $\mathrm{Ca}(\mathrm{OH})_{2}$ group on days 1, 3 and 7 compared with those in the other groups. In conclusion, PRF and CGF may be potential pulp-capping materials for vital pulp therapy. Future in vivo studies are required to confirm this.
\end{abstract}

\section{Introduction}

Direct dental pulp capping and vital pulpotomy are the two most commonly used vital pulp preservative treatment methods for permanent teeth without irreversible pulpitis. Such dental procedures aim to preserve dental pulp tissue, maintain the

Correspondence to: Professor Deqin Yang, Department of Conservative Dentistry and Endodontics, Stomatological Hospital of Chongqing Medical University, 426 Song Shi Bei Lu, Chongqing 401147, P.R. China

E-mail: 500246@hospital.cqmu.edu.cn

*Contributed equally

Key words: apoptosis, concentrated growth factors, dental pulp cells, platelet-rich fibrin, proliferation physiological function of the dentine-pulp complex and guarantee root development in immature teeth. During vital pulp therapy, an adequate pulp-capping agent is used and placed directly on the dental pulp tissue; therefore, biocompatibility and cytotoxicity require to be fully evaluated prior to use of a novel material as a pulp-capping agent.

Calcium hydroxide $\left(\mathrm{Ca}(\mathrm{OH})_{2}\right)$ has been used as a pulp-capping agent for decades and is the most popular material for vital pulp therapy (1). Mineral trioxide aggregate (MTA) is a bioactive material with a high sealing ability, superior antibacterial properties and excellent biocompatibility (2). iRoot BP plus (Innovative BioCeramix Inc.) is a convenient, ready-to-use nanoparticulate bioceramic. Despite recently being applied as a pulp-capping agent (3), iRoot BP has not been widely used in vital pulp therapy and the supporting evidence for its use is relatively less than that for the use of MTA and $\mathrm{Ca}(\mathrm{OH})_{2}$. Previous research has indicated that iRoot BP exhibited good biocompatibility with pulp tissue and induced proliferation and reparative dentin bridge formation in dental pulp cells (4), suggesting that iRoot BP may be used as a pulp-capping agent.

Platelet-rich fibrin (PRF), which belongs to the second generation of platelet concentrate products, has favorable properties, including osteogenic ability, simple preparation and no added biological agents. PRF was demonstrated to promote cell proliferation and osteogenic differentiation in human dental pulp cells (HDPCs) (5). Concentrated growth factors (CGF) are also derived from autologous blood and produced using a centrifuge device (Medifuge Silfradent srl). The different centrifugation speeds permit the isolation of fibrin matrix that is markedly larger, denser and richer in growth factors, as compared with past-generation platelet concentrate products (6). CGF contains numerous growth factors with advantages including osteogenic ability, simple preparation process, good biological properties and lack of added biological agents. Although it was previously hypothesized that PRF and CGF may be effective pulp-capping agents (5), evidence support this remains insufficient.

To the best of our knowledge, no previous study has compared these materials on dental pulp capping simultaneously. Prior to in vivo experiments, the influence of these materials on HDPCs requires to be investigated in vitro. 
Therefore, the aim of the present study was to investigate and compare the effect of $\mathrm{Ca}(\mathrm{OH})_{2}$, MTA, iRoot BP, PRF and CGF on the proliferation, viability, cell cycle, apoptosis and mineralization of HDPCs.

\section{Materials and methods}

Isolation and culture of HDPCs. The present study was approved by the Ethics Committee of Chongqing Medical University (Chongqing, China) and written informed consent was obtained from each donor. Freshly-extracted human impacted third molars were collected from the Stomatological Hospital of Chongqing Medical University (Chongqing, China). The pulp tissue was isolated from the teeth, cut into $1-\mathrm{mm}^{3}$ pieces, enzymatically digested for $50 \mathrm{~min}$ at $37^{\circ} \mathrm{C}$ with $3 \mathrm{mg} / \mathrm{ml}$ Type I collagenase (Gibco; Thermo Fisher Scientific, Inc.) and then supplemented with fetal bovine serum (FBS; Gibco; Thermo Fisher Scientific, Inc.). The digested tissue was pelleted by centrifugation at $201 \mathrm{x} \mathrm{g}$ for $5 \mathrm{~min}$ at room temperature. The cells were then resuspended in $1.5 \mathrm{ml} \alpha$-Minimum Essential Medium ( $\alpha$-MEM; Hyclone; GE Healthcare Life Sciences) containing 10\% FBS, $100 \mathrm{U} / \mathrm{ml}$ penicillin and $100 \mu \mathrm{g} / \mathrm{ml}$ streptomycin, transferred into a $25-\mathrm{cm}^{2}$ culture flask (cat. no. 430372; Corning Inc.), and then cultured at $37^{\circ} \mathrm{C}, 20 \% \mathrm{O}_{2}$ and $5 \% \mathrm{CO}_{2}$. After $24 \mathrm{~h}$ of incubation, $2.5 \mathrm{ml}$ culture medium was added, and the medium was changed every 3-4 days. When passaging the cells, a mixture of $0.25 \%$ trypsin and $0.01 \%$ EDTA was used. The expression of CD markers in these HDPCs was analyzed and published in a previous study by our group (7). For all experiments, the HDPCs were in passages 3-6.

Preparation of RPF and CGF. Venous blood was drawn from healthy volunteers and divided into $10-\mathrm{ml}$ sterile vacuum blood tubes (Sanli) without anti-coagulants. To prepare PRF, blood samples were immediately placed in a centrifuge (5810R; Eppendorf) for centrifugation. The program was run for $10 \mathrm{~min}$ at $1,811 \mathrm{x} \mathrm{g}$ and the fresh whole blood was divided into three layers. The intermediate filament protein gel layer was collected. For the preparation of CGF, blood samples were immediately placed in a centrifuge (Medifuge Silfradent srl) for centrifugation. The in-built program was run as follows: $30 \mathrm{sec}$ for acceleration, $2 \mathrm{~min}$ at $408 \mathrm{x} \mathrm{g}$, $4 \mathrm{~min}$ at $323 \mathrm{x} \mathrm{g}, 4 \mathrm{~min}$ at $408 \mathrm{x} \mathrm{g}, 3 \mathrm{~min}$ at $1,811 \mathrm{x} \mathrm{g}$ and $36 \mathrm{sec}$ for deceleration and stop. All centrifugation procedures were performed at room temperature. The fresh whole blood was divided into three layers and the intermediate layer was collected.

Preparation of PRF and CGF exudates. A sterile pre-fabricated mold (depth, $2 \mathrm{~mm}$; diameter, $5 \mathrm{~mm}$ ) was used to measure the same volume of five materials. The preparation of PRF and CGF exudate was similar to the methods described by Masuki et al (8). The same volume of PRF and CGF clots was placed on dry gauze to eliminate excessive serum, transferred to freezing tubes and stored at $-80^{\circ} \mathrm{C}$. The frozen clots were ground using a sample grinder (Tissuelyser-48; Digital China Jinxin Technology Co., Ltd.), resuspended in $3 \mathrm{ml} \alpha$-MEM, fully mixed using a shaker and centrifuged at $453 \mathrm{x}$ g for $5 \mathrm{~min}$ at $4^{\circ} \mathrm{C}$ to obtain PRF and CGF exudates.
The exudates were filtered using a $0.45-\mu \mathrm{m}$ sterile syringe filter (EMD Millipore) and stored at $-80^{\circ} \mathrm{C}$.

Preparation of the $\mathrm{Ca}(\mathrm{OH})_{2}, \mathrm{MTA}$ and iRoot BP exudates. $\mathrm{Ca}(\mathrm{OH})_{2}$ (DYCAL ${ }^{\circledR}$; Dentsply) and MTA (ProRoot MTA) were mixed according to the manufacturers' instructions. Prior to solidification, $\mathrm{Ca}(\mathrm{OH})_{2}$, MTA and iRoot BP were also used to fill the pre-fabricated mold to ensure that the same volume of each material was used. The same volume of solidified $\mathrm{Ca}(\mathrm{OH})_{2}$, MTA and iRoot BP was ground using a sample grinder (Tissuelyser-96; Digital China Jinxin Technology Co., Ltd) containing $3 \mathrm{ml} \alpha$-MEM, fully mixed using a shaker and then centrifuged at $453 \mathrm{x} \mathrm{g}$ for $5 \mathrm{~min}$ at room temperature to obtain exudates. All exudates from the three materials were filtered using a $0.45-\mu \mathrm{m}$ sterile syringe filter (EMD Millipore; Merck $\mathrm{KGaA}$ ) and stored at $4^{\circ} \mathrm{C}$ for no more than one month.

Cell viability. The effect of the five materials on the viability of HDPCs was assessed by trypan blue dye exclusion. HDPCs were seeded into 12 -well plates $\left(1 \times 10^{4}\right.$ cells/well), cultured overnight and treated with culture medium containing $10 \%$ exudate from $\mathrm{Ca}(\mathrm{OH})_{2}$, MTA, iRoot, PRF or CGF for 1,3 or 7 days. $\alpha$-MEM only was used for the control group. The number of viable cells relative to that in the control group was calculated following $0.4 \%$ trypan blue dye staining. The cells that stained blue were considered non-viable. The assays were performed in triplicate.

Cell proliferation assay. The effect of the five materials on HDPC proliferation was assessed using a Cell Counting Kit-8 (CCK-8; Dojindo Molecular Technologies, Inc.). Cells were transferred into a 96-well plate $\left(1 \times 10^{3}\right.$ cells/well) and cultured for $4 \mathrm{~h}$. The wells were divided into 6 groups and a total of $10 \mu \mathrm{l}$ $\mathrm{Ca}(\mathrm{OH})_{2}$, MTA, iRoot BP, PRF, CGF exudate (all dissolved in $\alpha$-MEM) or $\alpha$-MEM without serum (control) was added to the corresponding wells. On days 1,3 or 7, the culture medium was discarded and $100 \mu \mathrm{l}$ culture medium plus $10 \mu \mathrm{l}$ CCK- 8 solution was added to each well. The plates were incubated in the dark for $2 \mathrm{~h}$ and the absorbance at $450 \mathrm{~nm}$ was measured using a microplate reader (Thermo Fisher Scientific, Inc.). The assays were performed in triplicate.

Cell apoptosis. The effect of the five materials on apoptosis of HDPCs was assessed using an Annexin V/propidium iodide (PI) assay. HDPCs were seeded in 6-well plates $\left(3 \times 10^{4}\right.$ cells/well), cultured overnight and treated with culture medium containing $10 \%$ exudate from $\mathrm{Ca}(\mathrm{OH})_{2}$, MTA, iRoot, PRF or CGF for 1,3 or 7 days. $\alpha$-MEM only was used for the control. The relative number of apoptotic HDPCs was calculated following Annexin V/PI binding. In brief, the medium was removed and the cells incubated with Alexa Fluor 488 annexin V/PI (Invitrogen ${ }^{\mathrm{TM}}$; Thermo Fisher Scientific, Inc.) to label apoptotic cells, according to the manufacturer's protocol. Subsequently, the cells were analyzed on a flow cytometer (BD Influx ${ }^{\mathrm{TM}}$; BD Biosciences) using BD FACS ${ }^{\mathrm{TM}}$ software (version 1.0.0.650; BD Biosciences). The assays were performed in triplicate.

Cell cycle. HDPCs were seeded in 6-well plates ( $3 \times 10^{4}$ cells/well), cultured overnight and treated with culture medium containing $10 \%$ exudate from $\mathrm{Ca}(\mathrm{OH})_{2}$, MTA, iRoot, PRF or CGF. The 


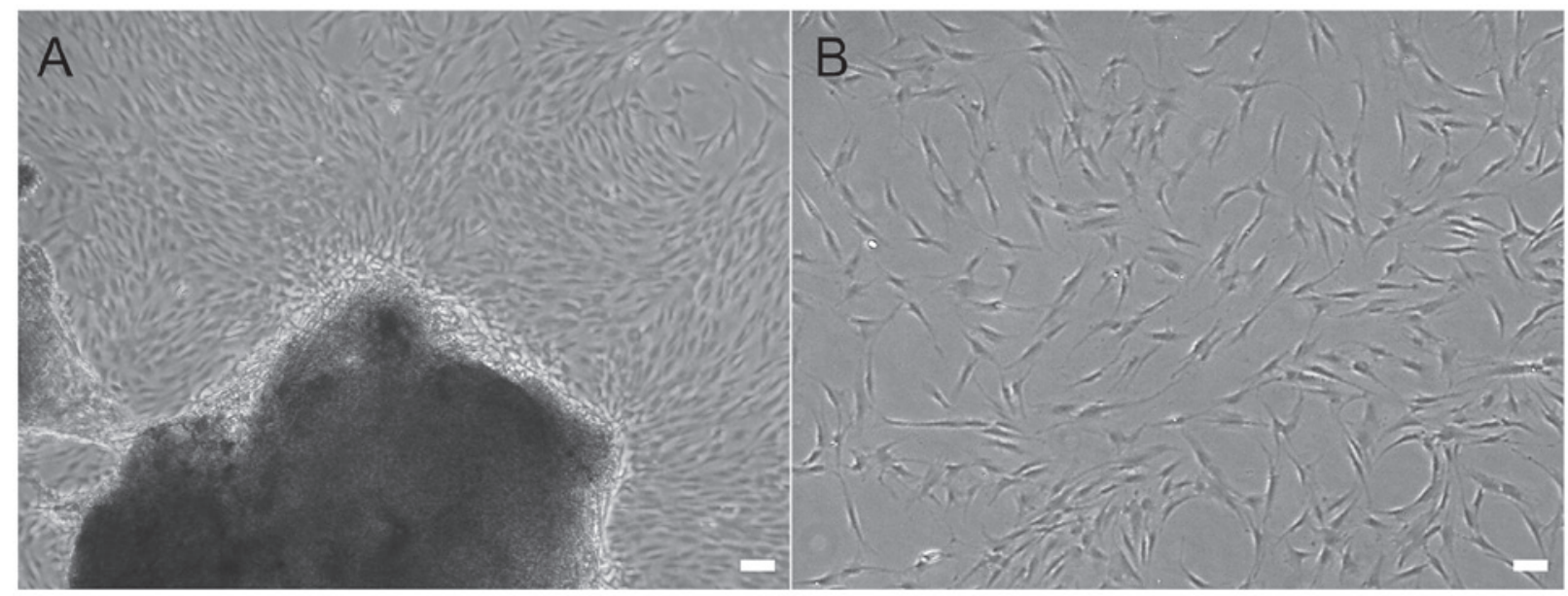

Figure 1. Morphology of isolated human dental pulp cells. (A) Primary culture of human dental pulp cells; (B) human dental pulp cells at passage 2 (scale bar, $20 \mu \mathrm{m})$.
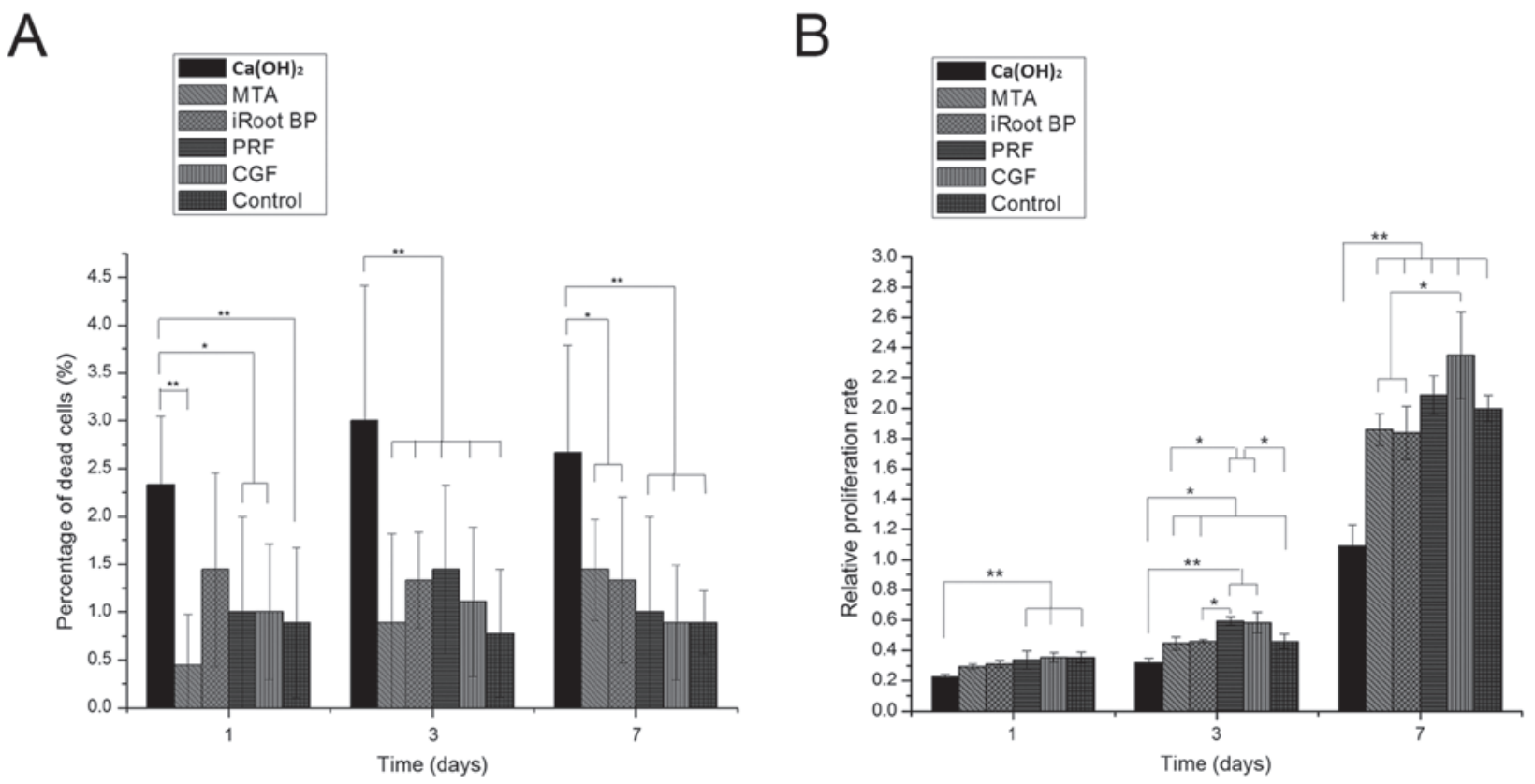

Figure 2. Effect of $\mathrm{Ca}(\mathrm{OH})_{2}$, MTA, iRoot BP, PRF and CGF on cell viability and proliferation. (A) Cell viability after treatment; (B) cell proliferation after treatment. $\mathrm{P}<0.05 ;{ }^{* *} \mathrm{P}<0.01 . \mathrm{Ca}(\mathrm{OH})_{2}$, calcium hydroxide; MTA, mineral trioxide aggregate; PRF, platelet-rich fibrin; CGF, concentrated growth factors.

same volume of culture medium was used for the control. On days 1,3 and 7 , the cells were trypsinized, transferred into sampling tubes, and reagent $\mathrm{A}, \mathrm{B}$ and $\mathrm{C}$ was added successively, according to the instructions of the Cell Cycle Analysis kit (NewMed Cytomics, Co. Ltd.). Cells were then analyzed on a flow cytometer using BD FACS ${ }^{\mathrm{TM}}$ software (version 1.0.0.650; BD Biosciences). The data were analyzed using Modfit software 3.1 (Verity Software House).

Alkaline phosphatase (ALP) activity. HDPC mineralization was evaluated by measuring the ALP activity. HDPCs were seeded in 96-well plates $\left(1 \times 10^{3}\right.$ cells/well), cultured overnight and treated with $\mathrm{Ca}(\mathrm{OH})_{2}$, MTA, iRoot, PRF or CGF exudates for 1 , 3 or 7 days. $\alpha$-MEM was used for the control. To quantitatively assess the ALP activity of cells, an ALP Assay kit (Beyotime
Institute of Biotechnology) was used according to the manufacturer's protocol. The absorbance at indicated time-points was measured at $405 \mathrm{~nm}$ using a 96-well plate reader (Thermo Fisher Scientific, Inc.). Each assay was performed in three wells and the experiments were performed in triplicate.

Statistical analysis. SPSS 22.0 software (IBM Corp.). Statistical analysis was performed using one-way analysis of variance followed by Tukey's post-hoc test. $\mathrm{P}<0.05$ was considered to indicate a statistically significant difference.

\section{Results}

Cell viability and proliferation. The HDPCs exhibited a fibroblastic appearance and epithelioid shapes (Fig. 1). According 

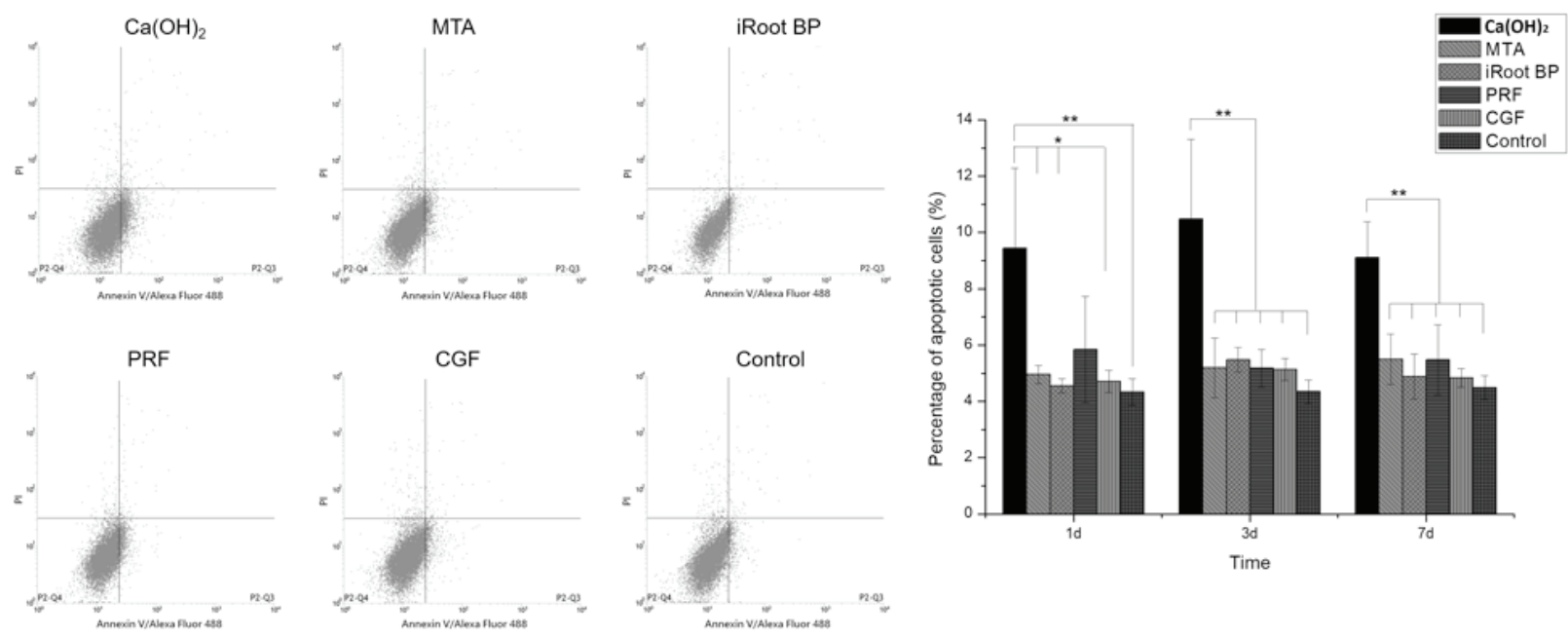

Figure 3. Effect of $\mathrm{Ca}(\mathrm{OH})_{2}$, MTA, iRoot BP, PRF and CGF on cell apoptosis. ${ }^{*} \mathrm{P}<0.05 ;{ }^{* *} \mathrm{P}<0.01 . \mathrm{Ca}(\mathrm{OH})_{2}$, calcium hydroxide; MTA, mineral trioxide aggregate; PRF, platelet-rich fibrin; CGF, concentrated growth factors; d, days; Q, quadrant.
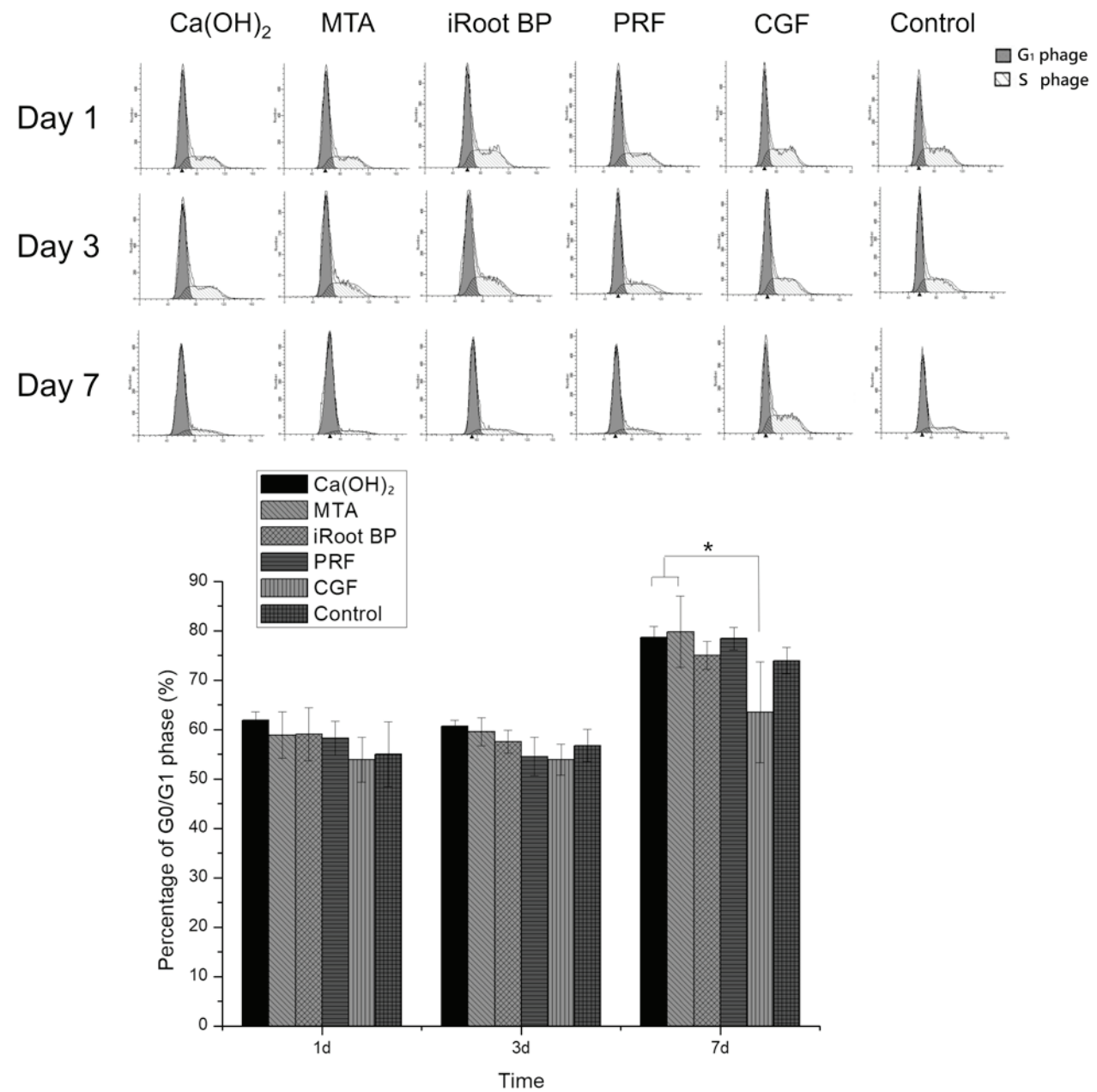

Figure 4. Effect of $\mathrm{Ca}(\mathrm{OH})_{2}$, MTA, iRoot BP, PRF and CGF on cell cycle progression. " $\mathrm{P}<0.05 . \mathrm{Ca}(\mathrm{OH})_{2}$, calcium hydroxide; MTA, mineral trioxide aggregate; PRF, platelet-rich fibrin; CGF, concentrated growth factors.

to the results of the trypan blue exclusion assay, nearly all detected materials except $\mathrm{Ca}(\mathrm{OH})_{2}$ displayed low toxicity to HDPC. A higher percentage of dead cells was detected in the
$\mathrm{Ca}(\mathrm{OH})_{2}$ group as compared with that in the other five groups on days 1,3 and 7 ( $\mathrm{P}<0.05$; Fig. $2 \mathrm{~A})$. The results of the CCK- 8 assay suggested that $\mathrm{Ca}(\mathrm{OH})_{2}$ significantly inhibited HDPC 
growth and proliferation as compared with the control group on days 1,3 and $7(\mathrm{P}<0.05)$. In contrast, $\mathrm{CGF}$ and PRF significantly promoted cell proliferation compared with the control group on days $3(\mathrm{P}<0.05)$. In the PRF group, the proliferation rate was higher as compared with that in the MTA and iRoot $\mathrm{BP}$ groups on day $3(\mathrm{P}<0.05)$. However, no significant differences were identified between MTA and iRoot BP or CGF and PRF on days 1, 3 and 7 (Fig. 2B).

Apoptotic rate. According to the results of the Annexin V assay, there was a higher percentage of apoptotic cells in the $\mathrm{Ca}(\mathrm{OH})_{2}$ group, as compared with that in the MTA, iRoot BP and CGF groups on days 1,3 and $7(\mathrm{P}<0.05) . \mathrm{Ca}(\mathrm{OH})_{2}$ treatment also increased the apoptotic rate as compared with PRF on days 3 and $7(\mathrm{P}<0.05)$. However, no significant differences were identified among the iRoot BP, MTA, CGF and PRF groups at any of the time-points (Fig. 3).

Cell cycle. The cell cycle analysis revealed that the CGF groups, there were less cells in $\mathrm{G}_{0} / \mathrm{G}_{1}$-phase as compared with those in the $\mathrm{Ca}(\mathrm{OH})_{2}$ and MTA groups on day $7(\mathrm{P}<0.05)$. No significant differences were identified among the six groups on days 1 and 3 (Fig. 4).

ALP activity. On day 1, the highest level of ALP activity was observed in the MTA group; MTA significantly enhanced ALP activity as compared with that in the CGF and control groups $(\mathrm{P}<0.05)$. On day 3 , the level of ALP activity in the MTA group was higher compared with that in the control groups $(\mathrm{P}<0.05)$. On day 7 , the ALP activity in the CGF group increased and was significantly higher than that in the $\mathrm{Ca}(\mathrm{OH})_{2}$ group $(\mathrm{P}<0.05$; Fig. 5). No significant differences were observed between any other two groups.

\section{Discussion}

The results of the present study provided important information on the biocompatibility and cytotoxicity of three commercially available and two potential materials for vital pulp capping. All materials except for $\mathrm{Ca}(\mathrm{OH})_{2}$ demonstrated good biocompatibility with HDPCs. None of MTA, iRoot BP, PRF and CGF significantly affected cell viability, cell death and apoptosis, as compared with the control group. Of note, the toxicity of $\mathrm{Ca}(\mathrm{OH})_{2}$ to HDPCs was relatively higher than that of the other materials. $\mathrm{Ca}(\mathrm{OH})_{2}$ significantly increased the number of dead or apoptotic cells and inhibited the proliferation of HDPCs. With regard to cytotoxicity and biocompatibility, MTA, iRoot $\mathrm{BP}, \mathrm{PRF}$ and CGF qualify for direct dental pulp-capping in vital pulp preservation. These results may assist clinicians in applying and developing vital pulp preservation therapies.

In the present study, three commercial dental materials available in dental clinics throughout China, as well as two potential materials for vital pulp capping were assessed. Although PRF and CGF have not been clinically applied in direct pulp capping or pulpotomy, they have potential as pulp-capping agents. These materials are isolated from autologous blood and are highly biocompatible. Their cytotoxicity is negligible and they have previously been proved to be effective for bone repair (9). As natural scaffolds, PRF and CGF are degradable and may be replaced by newly-formed tissue (10).

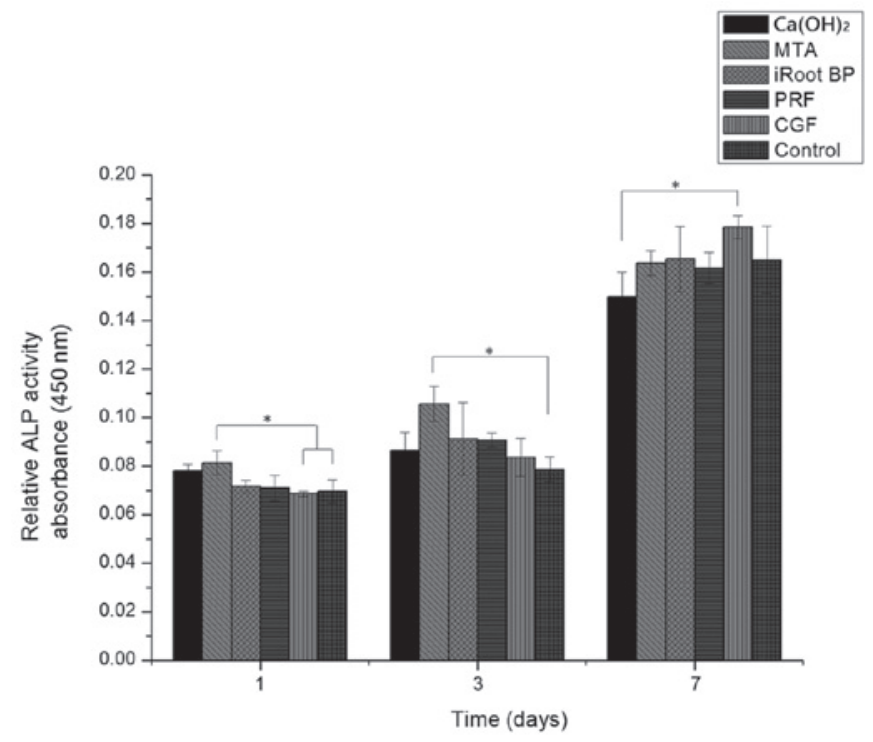

Figure 5. Effect of $\mathrm{Ca}(\mathrm{OH})_{2}$, MTA, iRoot BP, PRF and CGF on ALP activity of human dental pulp cells. ${ }^{*} \mathrm{P}<0.05$. $\mathrm{Ca}(\mathrm{OH})_{2}$, calcium hydroxide; MTA, mineral trioxide aggregate; PRF, platelet-rich fibrin; CGF, concentrated growth factors; ALP, alkaline phosphatase.

Different from platelet-rich plasma (PRP) as the 1st-generation platelet-derived product, the addition of dissimilar thrombin and anti-coagulant was not necessary for the preparation of PRF and CGF. The application of PRF or CGF does not pose any risks for immune rejection and transmission of infectious diseases. PRP was not considered a potential pulp-capping material in the present study, since the additive during PRP preparation may cause adverse effects (8). The biocompatibility of PRF and CGF on HDPCs has been confirmed in the present in vitro study. PRF and CGF were as effective as the widely-accepted MTA when in direct contact with the cells, and were even superior to MTA in promoting cell proliferation. Certain studies also indicated that PRF increases HDPC proliferation and differentiation $(5,11)$, which is consistent with the results of the present study. PRF has been applied in vital pulp therapy in a preclinical trial (12) and a case report (13), where good outcomes were suggested. The application of CGF in vital pulp therapy is rare and the effect of CGF on HDPC has remained to be determined. The present study demonstrated that CGF exhibited perfect biocompatibility with HDPC and compared CGF with other commercial pulp-capping materials. The results of the present study supported the application potential of CGF and PRF in vitro. Further in vivo studies are required.

HDPC mineralization was evaluated by measuring ALP activity. ALP activity is a vital test index for mineralization. A higher level of ALP activity usually correlates with a higher capacity for dentine bridge formation, which is important in direct pulp capping (14). PRF and CGF have a similar capacity to promote mineralization to that of MTA, implying that PRF and CGF may have a positive effect on reparative dentin formation. iRoot BP displayed an equal capacity to induce mineralization as MTA, which was consistent with the results of previous studies $(4,14)$. The study by Zhang et al (14) demonstrated that iRoot BP and MTA optimized the mineralization ability of HDPC, while another study reported on the use of iRoot 
BP to achieve favorable effects on reparative dentin formation in vivo (4). iRoot $\mathrm{BP}$ is more convenient to use than MTA and $\mathrm{Ca}(\mathrm{OH})_{2}$, and may be considered an alternative to MTA as a pulp-capping agent.

In the present study, the cytotoxicity of five pulp-capping materials was evaluated. Of note, HDPCs were treated with the exudates of these materials, a method also adopted in previous studies (15-17). Another study assessed the cytotoxicity of pulp-capping materials by directly seeding the cells onto the materials evaluating the cytotoxicity (14). In a preliminary experiment for the present study, it was attempted to pack these materials at the bottom of 96-well plates and seed the cells directly onto the packed materials. However, due to the opaque nature of the materials, it was impossible to observe the condition of the seeded cells under the microscope. In addition, a large number of cells appeared to die when in direct contact with $\mathrm{Ca}(\mathrm{OH})_{2}$. Furthermore, it was considerably difficult to digest and collect all cells in the dishes, particularly the cells that were partly inside the materials. Under these circumstances, it was not possible to accurately determine the total number of viable cells and percentages of dead and apoptotic cells. Therefore, in the present study, HDPCs were treated with exudates from different materials, similar to previous studies $(8,17)$.

Different from the calcium and silicon ions released by MTA and iRoot BP, PRF and CGF are able to directly release a variety of growth factors closely involved in the processes of cell growth, proliferation, pro-inflammation and angiogenesis (18). The released factors contain transforming growth factor- $\beta$, platelet-derived growth factor, vascular endothelial growth factor, interleukin-1 $\beta$ and interleukin-6 (8). When placed on the exposed dental pulp tissue, PRF and CGF are expected to function not only as a scaffolding material but also as a reservoir to deliver certain growth factors and pro-inflammatory cytokines at the implantation sites. In addition, PRF and CGF are collected from autologous blood, which, in theory, means that they cannot cause any rejective reactions.

Previous studies investigated the cytotoxicity of MTA, $\mathrm{Ca}(\mathrm{OH})_{2}$ and iRoot BP to HDPCs, as well as the effectiveness of these materials in vivo. $\mathrm{Ca}(\mathrm{OH})_{2}$ may cause necrosis and apoptosis of nearby cells and create an alkaline environment to induce dentine bridge formation (19). MTA has a higher success rate and results in a lesser pulpal inflammatory response and more predictable hard dentin bridge formation than $\mathrm{Ca}(\mathrm{OH})_{2}(20,21)$. MTA and iRoot BP exhibited acceptable biocompatibility to HDPC in vitro (14) and a similar efficacy in vital pulpotomy treatment (22). The present study compared these materials simultaneously and provided data for dental clinicians.

There are certain limitations. In the present study, a pre-fabricated mould was also designed to guarantee the identical volume of different materials used. Although the concentrations of different materials were consistent, it is still necessary to compare the influence of different concentrations of materials. Furthermore, the maximum observation time was 7 days, which referred to certain previous studies $(17,23)$. Inevitable passaging of cells in vitro may limit the evaluation time. In vitro study usually comprises evaluation of the toxicity of these materials in the short term. In the future, in vivo studies will be performed for long-term evaluation.

In conclusion, under the experimental conditions of the present study, all of the five materials except $\mathrm{Ca}(\mathrm{OH})_{2}$ were indicated to be biocompatible with HDPC. PRF and CGF are potential pulp-capping materials for vital pulp therapy. Further study on the effectiveness of PRF and CGF as vital pulp-capping agents in vivo is required.

\section{Acknowledgements}

Not applicable.

\section{Funding}

The study was supported by the National Natural Science Foundation of China (grant nos. 81800958 and 31571508) and Yuzhong District Science and Technology Commission in Chongqing (grant no. 20180119).

\section{Availability of data and materials}

The datasets used and/or analyzed during the current study are available from the corresponding author on reasonable request.

\section{Authors' contributions}

DY conceived and designed the experiments; LD and QY performed the experiments and analyzed the data; LD wrote the manuscript.

\section{Ethics approval and consent to participate}

The present study was approved by the Ethics Committee of Chongqing Medical University (Chongqing, China) and written informed consent was obtained from each donor.

\section{Patient consent for publication}

Not applicable.

\section{Competing interests}

The authors declare that they have no competing interests.

\section{References}

1. Mente J, Hufnagel S, Leo M, Michel A, Gehrig H, Panagidis D, Saure D and Pfefferle T: Treatment outcome of mineral trioxide aggregate or calcium hydroxide direct pulp capping: Long-term results. J Endod 40: 1746-1751, 2014.

2. Parirokh $\mathrm{M}$ and Torabinejad M: Mineral trioxide aggregate: A comprehensive literature review-part I: Chemical, physical, and antibacterial properties. J Endod 36: 16-27, 2010.

3. Shi S, Bao ZF, Liu Y, Zhang DD, Chen X, Jiang LM and Zhong M: Comparison of in vivo dental pulp responses to capping with iRoot BP Plus and mineral trioxide aggregate. Int Endod J 49: 154-160, 2016

4. Liu S, Wang S and Dong Y: Evaluation of a bioceramic as a pulp capping agent in vitro and in vivo. J Endod 41: 652-657, 2015.

5. Huang FM, Yang SF, Zhao JH and Chang YC: Platelet-rich fibrin increases proliferation and differentiation of human dental pulp cells. J Endod 36: 1628-1632, 2010.

6. Durmuşlar MC, Balli U, Dede FÖ, Misir AF, Bariş E, Kürkçü M and Kahraman SA: Histological evaluation of the effect of concentrated growth factor on bone healing. J Craniofac Surg 27: 1494-716, 2016. 
7. Dou L, Yan Q, Liang P, Zhou P, Zhang Y and Ji P: iTRAQ-based proteomic analysis explore the influence of hypoxia on the proteome of dental pulp stem cells under 3D culture. Proteomics: 18, 2018.

8. Masuki H, Okudera T, Watanebe T, Suzuki M, Nishiyama K, Okudera H, Nakata K, Uematsu K, Su CY and Kawase T: Growth factor and pro-inflammatory cytokine contents in platelet-rich plasma (PRP), plasma rich in growth factors (PRGF), advanced platelet-rich fibrin (A-PRF), and concentrated growth factors (CGF). Int J Implant Dent 2: 19, 2016.

9. Takeda Y, Katsutoshi K, Matsuzaka K and Inoue T: The effect of concentrated growth factor on rat bone marrow cells in vitro and on calvarial bone healing in vivo. Int J Oral Maxillofac Implants 30: 1187-1196, 2015.

10. Isobe $\mathrm{K}$, Watanebe T, Kawabata H, Kitamura Y, Okudera T, Okudera H, Uematsu K, Okuda K, Nakata K, Tanaka T and Kawase T: Mechanical and degradation properties of advanced platelet-rich fibrin (A-PRF), concentrated growth factors (CGF), and platelet-poor plasma-derived fibrin (PPTF). Int J Implant Dent 3: 17, 2017.

11. Chen YJ, Zhao YH, Zhao YJ, Liu NX, Lv X, Li Q, Chen FM and Zhang M: Potential dental pulp revascularization and odonto-/osteogenic capacity of a novel transplant combined with dental pulp stem cells and platelet-rich fibrin. Cell Tissue Res 361: 439-455, 2015

12. Keswani D, Pandey RK, Ansari A and Gupta S: Comparative evaluation of platelet-rich fibrin and mineral trioxide aggregate as pulpotomy agents in permanent teeth with incomplete root development: A randomized controlled trial. J Endod 40: 599-605, 2014

13. Hiremath H, Saikalyan S, Kulkarni SS and Hiremath V: Second-generation platelet concentrate (PRF) as a pulpotomy medicament in a permanent molar with pulpitis: A case report. Int Endod J 45: 105-112, 2012.

14. Zhang S, Yang X and Fan M: BioAggregate and iRoot BP Plus optimize the proliferation and mineralization ability of human dental pulp cells. Int Endod J 46: 923-929, 2013.
15. Öncel Torun Z, Torun D, Demirkaya K, Yavuz ST, Elçi MP, Sarper M and Avcu F: Effects of iRoot BP and white mineral trioxide aggregate on cell viability and the expression of genes associated with mineralization. Int Endod J 48: 986-993, 2015.

16. Qiu W, Sun B, He F and Zhang Y: MTA-induced Notch activation enhances the proliferation of human dental pulp cells by inhibiting autophagic flux. Int Endod J 50 (Suppl 2): e52-e62, 2017.

17. Saeed MA, El-Rahman MA, Helal ME, Zaher AR and Grawish ME: Efficacy of human platelet rich fibrin exudate vs. fetal bovine serum on proliferation and differentiation of dental pulp stem cells. Int J Stem Cells 10: 38-47, 2017.

18. Qiao J, An N and Ouyang X: Quantification of growth factors in different platelet concentrates. Platelets 28: 774-778, 2017.

19. Luczaj-Cepowicz E, Marczuk-Kolada G, Pawinska M, Obidzinska M and Holownia A: Evaluation of cytotoxicity and $\mathrm{pH}$ changes generated by various dental pulp capping materials-an in vitro study. Folia Histochem Cytobiol 55: 86-93, 2017.

20. Li Z, Cao L, Fan M and Xu Q: Direct Pulp capping with calcium hydroxide or mineral trioxide aggregate: A meta-analysis. J Endod 41: 1412-1417, 2015.

21. Kundzina R, Stangvaltaite L, Eriksen HM and Kerosuo E: Capping carious exposures in adults: A randomized controlled trial investigating mineral trioxide aggregate versus calcium hydroxide. Int Endod J 50: 924-932, 2017.

22. Azimi S, Fazlyab M, Sadri D, Saghiri MA, Khosravanifard B and Asgary S: Comparison of pulp response to mineral trioxide aggregate and a bioceramic paste in partial pulpotomy of sound human premolars: A randomized controlled trial. Int Endod J 47: 873-881, 2014

23. Wu T, Shi Z, Song H, Li Y and Li JH: Cytotoxicity of local anesthetics on rabbit adipose-derived mesenchymal stem cells during early chondrogenic differentiation. Exp Ther Med 16: 2843-2850, 2018 